\title{
PERBANDINGAN HASIL PEMOLESAN ANTARA BAHAN POLES PUMICE DENGAN ABU GOSOK PADA GIGI TIRUAN LEPASAN AKRILIK
}

\author{
Sri Wahyuni*, Lies Elina* \\ *Jurusan Teknik Gigi Poltekkes Tanjungkarang
}

\begin{abstract}
Salah satu tahap yang penting dalam pembuatan basis akrilik adalah tahap finishing dan poleshing. Pada tahap ini digunakan alat dan bahan yang abrasif untuk menghilangkan guratan. Pumice merupakan bahan yang biasa digunakan untuk menghaluskan permukaan. Selain pumice, terdapat bahan abu gosok yang belum pernah digunakan namun mempunyai komposisi bahan yang hampir sama dengan pumice dan tekstur yang lebih kasar sehingga bisa menggantikan pumice. Penelitian ini merupakan penelitian eksperimental menggunakan sampel sebanyak 27 buah lempengan akrilik dengan 2 permukaan yang mempunyai ukuran (tinggi : $3 \mathrm{~mm}$, panjang : $4 \mathrm{~cm}$, dan lebar $3 \mathrm{~cm}$ ). Pada setiap permukaan sampel akan dipoles dengan 2 bahan yang berbeda yaitu pumice dan abu gosok dengan waktu yang berbeda yaitu $<10$ menit, 10 menit, $>10$ menit. Analisis yang digunakan dalam penelitian ini adalah univariat dengan menampilkan hasil penelitian yang telah dilakukan kemudian diuraikan secara deskriptif dan bivariat dengan tes Anova. Hasil dari penelitian didapatkan variabel waktu dan bahan berpengaruh signifikan secara bersama-sama terhadap hasil pemolesan gigi tiruan akrilik.Kesimpulannya Pemolesan dengan abu gosok pada waktu $<10$ menit sudah dapat menghasilkan permukaan gigi tiruan yang halus dan lebih mengkilap, sedangkan pumice membutuhkan waktu 10 menit untuk menghasilkan permukaan yang halus dan mengkilap. Disarankan Jurusan Teknik gigi dapat menggunakan abu gosok sebagai pengganti bahan pumice untuk menghemat biaya praktikum.
\end{abstract}

Kata Kunci: Pumice, Abu Gosok, Akrilik

\section{LATAR BELAKANG}

Gigi tiruan lepasan adalah gigi tiruan yang menggantikan satu atau lebih gigi dan jaringan sekitarnya, yang dapat dikeluar masukkan kedalam mulut oleh pemakainya dan dikenal dengan istilah removable denture (Itjiningsih, 1991:1).

Bahan yang dgunakan untuk pembuatan gigi tiruan lepasan lebih banyak menggunakan resin akrilik karena beberapa pertimbangan yang menguntungkan untuk pengguna. Dari hasil penelitian epidemiologis di negara Belanda, persentase penggunaan gigi tiruan akrilik mencapai 69\% karena dapat di tanggung Asuransi (Battistuzzi, 1996:3).

Dalam pembuatan gigi tiruan lepasan akrilik, tahap akhir yang harus dilakukan adalah finishing dan polishing untuk membentuk gigi tiruan halus dan mengkilap (Itjiningsih, 1991:187). Permukaan gigi tiruan akrilik yang halus dan mengkilap dapat mencegah penumpukan sisa makanan sehingga lebih mudah dibersihkan. Pasien juga tidak dapat menerima adanya permukaan kasar karena merasa tidak nyaman (Combe, 1992:519).

Untuk menghaluskan basis gigi tiruan akrilik, semua guratan dan daerah kasar harus dibuang dengan alat-alat dan bahan yang abrasif. Bahan abrasif berperan untuk proses pengikisan permukaan atau grinding. (Philips, 2004:263).

Ada beberapa jenis alat dan bahan yang digunakan pada tahap finishing dan polishing, salah satunya adalah pumice dengan menggunakan alat feltcone dan sikat hitam. Sejalan perkembangan ilmu pengetahuan pembuatan gigi tiruan akrilik, bahan poles pumice dapat digantikan dengan bahan lain yaitu abu gosok.

Pada penelitian sebelumnya dengan judul "Perbedaan Kekasaran Permukaan Heat Cured dan Self Cured Acrylic Resin yang dipoles dengan Pumice, Abu Gosok dan Tanpa Bahan Poles“ didapatkan perbedaan yang bermakna antara kekasaran permukaan Heat Cured dan Self Cured Acrylic Resin yang dipoles dengan Pumice, abu gosok dan tanpa bahan poles 
$(\mathrm{P}<0,05)$. Tingkat kekasaran permukaan kelompok Heat Cured lebih kecil dibandingkan dengan Self Cured dan kekasaran permukaan yang dipoles pumice lebih kecil dengan abu gosok dan tanpa bahan poles, demikian juga abu gosok mempunyai nilai kekasaran yang lebih kecil dari pada tanpa bahan poles. (Sherly,dkk,2012)

Berdasarkan pengalaman dari Praktik Kerja Nyata yang penulis supervisi di RSPAD Gatot Soebroto Jakarta Pusat, gigi tiruan lepasan akrilik dipoles dengan menggunakan abu gosok untuk menggantikan bahan poles pumice. Menurut salah satu tekniker gigi di RSPAD , proses pemolesan dapat dilakukan dalam waktu yang lebih singkat dan hasilnya juga halus dan mengkilap .

Oleh karena itu,penulis ingin melakukan penelitian tentang perbandingan hasil pemolesan antara pumice dengan abu gosok pada gigi tiruan lepasan akrilik dan mana yang lebih efektif antara pemolesan dengan bahan poles pumice dan abu gosok.

\section{METODE}

Jenis penelitian yang digunakan adalah penelitian eksperimental dengan melakukan kegiatan percobaan di laboratorium. Dengan jumlah sampel percobaan sebanyak 30 sampel gigi buatan.

Pengumpulan data diambil melalui metode observasi (pengamatan), eksperimental yang dilakukan dengan mengikuti tahapan sebagai berikut:

1. Semua yang diperlukan dalam pengamatan dipersiapkan terlebih dahulu, seperti alat dan bahan yang akan digunakan dalam penelitian, lempeng akrilik dibagi menjadi tiga agar lebih mudah saat proses pemolesan.

2. Timbang bahan dengan menggunakan timbangan digital dan gunakan gelas ukur untuk mengukur air yaitu dengan rasio W/P pumice $3: 5$ (15 ml, 25 gram), abu gosok 12:5 (60 ml, 25 gram), dan $\mathrm{CaCO}_{3}$ 3:1 (8 ml, 25 gram) setelah itu pasang feltcone, sikat hitam dan white brush pada masing-masing tuas dari mesin poles, atur kecepatan dari mesin poles yaitu $3400 \mathrm{rpm}$.

3. Proses pemolesan dilakukan dengan waktu yang berbeda menggunakan pumice pada satu sisi permukaan dan abu gosok pada satu permukaan. Waktu pemolesan ada 3 kategori yaitu cepat < 10 menit, normal 10 menit, lambat > 10 menit untuk setiap alatnya. Setelah dilakukan pemolesan, cuci dan ukur hasilnya dengan menggunakan aliran air, goresan pena dan rabaan.

4. Setelah masing-masing permukaan dipoles, beri tanda pada setiap permukaan kemudian catat dan amati hasil pemolesan sesuai dengan waktu yang ditentukan.

5. Pengulangan percobaan suatu penelitian dianggap telah cukup baik bila memenuhi persamaan dibawah ini:

$$
(\mathrm{t}-1)(\mathrm{r}-1) \geq 15
$$

Keterangan :

$$
\begin{aligned}
& t=\text { jumlah perlakuan } \\
& r=\text { jumlah pengulangan } \\
& (t-1)(r-1) \geq 15 \\
& (3-1)(r-1) \geq 15 \\
& (2)(r-1) \geq 15 \\
& 2 r-2 \geq 15 \\
& 2 r \geq 15+2 \\
& 2 r \geq 17 \\
& r=17 / 2 \\
& r=9
\end{aligned}
$$

Jumlah pengulangan yang dilakukan dalam penelitian ini adalah sebanyak 9 kali (Hanafiah, 2011:9).

Selanjutnya data diolah dan dianalisis secara univariat dengan menampilkan hasil penelitian untuk mengetahui perbandingan hasil pemolesan antara pumice dengan abu gosok pada gigi tiruan lepasan akrilik yang diuraikan secara deskriptif. Sedangkan analisis bivariat dilakukan untuk melihat efektifitas antara bahan poles pumice dengan abu gosok pada pembuatan gigi tiruan lepasan akrilik dengan uji anova. 
HASIL

\section{Analisis Univariat}

$\begin{array}{lrr}\text { Tabel 1: Distribusi } & \text { Frekuensi } & \text { Untuk } \\ \text { Pumice dan } & \text { Abu } & \text { gosok } \\ \text { Berdasarkan Waktu Poles } & \end{array}$

\begin{tabular}{|c|c|c|c|}
\hline $\begin{array}{l}\text { Waktu } \\
\text { Poles }\end{array}$ & Bahan & Rata-Rata Hasil & $\mathrm{f}$ \\
\hline \multirow[b]{2}{*}{$\begin{array}{l}\text { Normal } \\
10 \mathrm{mnt}\end{array}$} & Pumice & Halus dan mengkilap & $9 \mathrm{kali}$ \\
\hline & $\begin{array}{l}\text { Abu } \\
\text { gosok }\end{array}$ & $\begin{array}{l}\text { Lebih halus dan lebih } \\
\text { mengkilap }\end{array}$ & 9 kali \\
\hline \multirow{3}{*}{$\begin{array}{l}\text { Cepat } \\
<10 \\
\text { mnt }\end{array}$} & Pumice & $\begin{array}{l}\text { Lebih gurat dan } \\
\text { mengkilap }\end{array}$ & 9 kali \\
\hline & $\mathrm{Abu}$ & $\begin{array}{l}\text { Sedikit gurat \& lebih } \\
\text { mengkilap }\end{array}$ & 3 kali \\
\hline & & Halus \& lebih mengkilap & $6 \mathrm{kali}$ \\
\hline \multirow{2}{*}{$\begin{array}{l}\text { Lambat } \\
>10 \\
\text { mnt }\end{array}$} & Pumice & Halus dan mengkilap & 9 kali \\
\hline & $\begin{array}{l}\text { Abu } \\
\text { gosok }\end{array}$ & $\begin{array}{l}\text { Lebih halus dan lebih } \\
\text { mengkilap }\end{array}$ & 9 kali \\
\hline
\end{tabular}

\section{Analisis Bivariat}

Tabel 2: Efektifitas Bahan Poles Antara Waktu dan Hasil

\begin{tabular}{lc}
\hline \multicolumn{1}{c}{ Uji Waktu dan Hasil } & p value \\
\hline Uji Normalitas Data & 0,077 \\
\hline Uji Anova & 0,000 \\
\hline
\end{tabular}

Pada tabel uji normalitas data terlihat hasil uji menunjukan bahwa varian ketiga kelompok tersebut sama ( $p$ value $=0,077$ ), sehingga uji Anova valid untuk menguji hubungan ini. Pada tabel ANOVA, kolom Sig. diperoleh nilai $\mathrm{P}$ (P-value $)=0,000$. Pada taraf nyata $=0,05$ kita menolak Ho, kesimpulannya adalah ada perbedaan yang bermakna rata-rata hasil polesan berdasarkan waktu pemolesan

Tabel 3: Efektifitas Bahan Poles Antara Bahan dan Hasil

\begin{tabular}{lc}
\hline \multicolumn{1}{c}{ Uji Bahan dan Hasil } & p value \\
\hline Uji Normalitas Data & .272 \\
\hline Uji Anova & .000 \\
\hline
\end{tabular}

Pada tabel uji normalitas data terlihat hasil uji menunjukan bahwa varian ketiga kelompok tersebut sama ( $p$ value $=0,272)$, sehingga uji Anova valid untuk menguji hubungan ini. Pada uji anova diperoleh nilai $p$ value $=0,000$. Pada taraf nyata $=$ 0,05 kita menolak Ho, kesimpulannya adalah ada perbedaan yang bermakna ratarata hasil polesan berdasarkan bahan poles.

\section{PEMBAHASAN}

Dalam penelitian ini didapat rata-rata hasil pemolesan pada setiap percobaan yang berbeda-beda dari percobaan pertama hingga percobaan kesembilan untuk masing-masing waktu dan bahan. Waktu pencapaian dari setiap bahan untuk mencapai syarat pemolesan basis akrilik juga berbeda.

Hasil pemolesan dengan waktu normal 10 menit, rata-rata hasil dari bahan pumice adalah halus dan mengkilap sedangkan abu gosok menghasilkan permukaan yang lebih halus dan mengkilap. Waktu pencapaian < 10 menit (cepat) rata-rata hasil permukaan poles untuk bahan pumice lebih gurat dan mengkilap sedangkan abu gosok halus dan lebih mengkilap. Pada waktu > 10 menit (lambat) permukaan poles yang dihasilkan pumice adalah halus dan mengkilap, namun abu gosok menghasilkan permukaan yang lebih halus dan lebih mengkilap .

Hasil tersebut menyatakan bahwa pemolesan menggunakan abu gosok pada waktu < 10 menit (cepat) sudah dapat menghasilkan permukaan yang halus dan lebih mengkilap, sedangkan pumice membutuhkan waktu 10 menit untuk menghasilkan permukaan yang halus dan mengkilap.

Dari hasil pemolesan tersebut didapatlah kekurangan dan kelebihan antara pumice dengan abu gosok. Kekurangan dari bahan pumice adalah mempunyai waktu pemolesan yang lebih lama untuk menghasilkan permukaan yang halus dan mengkilap, rata-rata hasil pemolesannya kurang begitu halus dan mengkilap dibandingkan dengan abu gosok. Harganya jualnya juga lebih mahal, dan hanya tersedia di toko dental suply yang menjual bahan-bahan kedokteran 
gigi. Adapun kelebihan dari pumice adalah proses pemolesan tidak telalu kotor karena partikel dari pumice lebih halus dan membutuhkan air yang lebih sedikit pada saat manipulasi, hasil pencampurannya lebih menyatu sehingga tidak mudah terpercik. Pada proses pemolesan kemungkinan bahan mengabrasi pemukaan plat akrilik lebih sedikit sehingga permukaan tidak menjadi tipis dan tidak gampang patah. Konduktifitas panas lebih rendah sehingga pada waktu pemolesan tidak menghasilkan panas yang berlebihan.

Kekurangan dari abu gosok adalah pada saat proses pemolesan lebih kotor karena partikelnya lebih kasar . Pada waktu manipulasi bahan membutuhkan air lebih banyak dan pencampurannya kurang menyatu sehingga pada saat digunakan abu dan air terpisah yang menyebabkan bahan mudah terpercik. Kelebihan abu gosok adalah mempunyai waktu pemolesan yang lebih cepat, hasilnya juga lebih halus dan lebih mengkilap karena tingkat kekasaran yang tinggi sehingga cepat dan lebih rata mengabrasi permukaan akrilik. Harganya jauh lebih murah dan banyak tersedia dipasar tradisional, warung-warung atau bisa mencarinya langsung di tempat pembakaran dan pabrik penggilingan padi.

Dalam penelitian ini didapat distribusi frekuensi hasil pemolesan dari percobaan pertama hingga percobaan kesembilan untuk masing-masing waktu dan bahan poles.

Pemolesan dengan waktu normal 10 menit untuk pumice didapatkan frekuensi 9 kali dengan hasil halus dan mengkilap, sedangkan abu gosok menghasilkan permukaan yang lebih halus dan mengkilap dengan frekuensi 9 kali. Waktu pencapaian < 10 menit (cepat) dari bahan pumice didapatkan frekuensi 9 kali dengan hasil permukaan poles lebih gurat dan mengkilap sedangkan abu gosok menghasilkan permukaan poles sedikit gurat dan lebih mengkilap sebanyak 3 kali serta halus dan lebih mengkilap sebanyak 6 kali. Pada waktu > 10 menit (lambat) dari bahan pumice didapatkan 9 kali dengan hasil permukaan poles halus dan mengkilap, namun abu gosok menghasilkan permukaan yang lebih halus dan lebih mengkilap dengan frekuensi 9 kali.

Hasil tersebut menyatakan bahwa pemolesan menggunakan abu gosok dengan waktu < 10 menit (cepat) lebih banyak menghasilkan permukaan yang halus dan lebih mengkilap, sedangkan pumice menghasilkan permukaan poles lebih gurat dan mengkilap.

\section{KESIMPULAN}

Penelitian ini menyimpulkan bahwa pemolesan dengan abu gosok pada waktu < 10 menit sudah dapat menghasilkan permukaan gigi tiruan yang halus dan lebih mengkilap, sedangkan pumice membutuhkan waktu 10 menit untuk menghasilkan permukaan yang halus dan mengkilap.

Kekurangan bahan pumice adalah membutuhkan waktu lebih lama untuk menghasilkan permukaan yang halus dan mengkilap dibandingkan abu gosok., harga lebih mahal, dan hanya tersedia di toko bahan-bahan kedokteran gigi. Adapun kelebihan pumice adalah proses pemolesan lebih bersih, permukaan akrilik tidak menjadi tipis serta konduktifitas panas lebih rendah dibandingkan abu gosok.

Pemolesan dengan abu gosok lebih cepat dan lebih banyak menghasilkan permukaan yang lebih halus dan lebih mengkilap dibandingkan dengan pumice.

Variabel waktu dan bahan berpengaruh signifikan secara bersama sama terhadap hasil pemolesan gigi tiruan akrilik. Ternyata abu gosok lebih efektif sebagai bahan poles dilihat dari mutu maupun waktu dibandingkan dengan pumice.

Berdasarkan kesimpulan di atas maka disarankan pada saat pemolesan, gigi tiruan lepasan akrilik harus benar-benar dalam kondisi yang halus untuk mendapatkan hasil pemolesan yang bagus dan cepat. Konsistensi bahan poles harus kental agar bahan lebih cepat 
mengabrasif. Jurusan Teknik gigi dapat menggunakan abu gosok sebagai pengganti bahan pumice untuk menghemat biaya praktikum.

\section{DAFTAR PUSTAKA}

Battistuzzi, P.G.F.C.M. (1996). Gigi Tiruan Sebagian. Ed Ke- 2. Jakarta:Widya Medika.
Combe, E.C. (1992). Sari Dental Material. diterjemahkan oleh drg. Slamat Tarigan, MS, Phd. Jakarta:Balai Pustaka.

Hanafiah, Kemas Ali. (2011). Rancangan Percobaan. Ed Ke- 3. Jakarta : Rajawali.

Ithjiningsih, W. H. (1991). Gigi Tiruan Lengkap Lepas. Jakarta: : EGC.

Phillips, R. W. (1971). Elements of Dental Materials. Philadelphia: W.B. Sounders Company. 